\title{
Effects of Anacardic Acid Monoene on the Respiratory System of Mice Submitted to Acute Respiratory Distress Syndrome
}

\author{
Fladimir de Lima Gondim ${ }^{1}$ (D) Ruth Mesquita Ferreira ${ }^{2}$ (D) - Tiago Rocha Nogueira ${ }^{3}$ (D) Daniel Silveira Serra $^{2}$ (I) \\ Maria Alexandra de Sousa Rios ${ }^{4}$. Antônia Torres Ávila Pimenta ${ }^{3}$ (1) - Francisco Sales Ávila Cavalcante ${ }^{2}$ (1)
}

Received: 28 December 2020 / Accepted: 9 April 2021 / Published online: 3 May 2021

(C) Sociedade Brasileira de Farmacognosia 2021

\begin{abstract}
The acute respiratory distress syndrome caused by viral pathogens is a worldwide public health emergency. It is suggested that patients with this condition should be screened using therapies that address the need to prevent mortality. Anacardic acids found in Anacardium species have biological activities related to the antioxidant capacity of their double bonds in the lateral alkyl chain. The present study seeks to investigate the effects of anacardic acid monoene on acute respiratory distress syndrome caused by lipopolysaccharides. Experiments were carried out on mice divided into three groups: control group, acute respiratory distressinduced group, and anacardic acid monoene pretreated group, subsequently, induced to acute respiratory distress by lipopolysaccharides. Results showed that anacardic acid moeno was able to prevent changes in lung function and preserve its mechanical properties from containing inflammatory cell infiltrate, collapse of alveoli, and decreased airway resistance, suggesting that this compound may be effective in preventing the acute respiratory distress syndrome caused by viral pathogens.
\end{abstract}

Keywords SARS-CoV-2 $\cdot$ COVID-19 $\cdot$ Acute lung injury $\cdot$ Pulmonary mechanics $\cdot$ Infection $\cdot$ Smooth muscle

\section{Introduction}

Currently, acute respiratory distress syndrome (ARDS) caused by viral pathogens, such as coronavirus-2 (SARSCoV-2), constitutes a worldwide public health emergency (WHO 2020). Lung infection, especially alveolar injury, is the primary cause of morbidity and mortality in SARS-CoV2 disease (COVID-19) (Zhou et al. 2020). Thus, it is suggested that patients with COVID-19 be promptly screened in

Fladimir de Lima Gondim

lima.gondim@aluno.uece.br

Maria Alexandra de Sousa Rios

https://orcid.org/0000-0002-3145-0456

1 Instituto Superior de Ciências Biomédicas, Universidade Estadual do Ceará, Fortaleza, Brasil

2 Centro de Ciências e Tecnologia, Universidade Estadual do Ceará, Fortaleza, Brasil

3 Departamento de Química Orgânica e Inorgânica, Universidade Federal do Ceará, Fortaleza, Brasil

4 Departamento de Engenharia Mecânica, Universidade Federal do Ceará, Fortaleza, Brasil order to prevent acute lung injury (ALI) and acute respiratory distress syndrome (ARDS), using therapies to meet the immediate need to avoid mortality (Ruan et al. 2020). The angiotensin converting enzyme contributes significantly to the interaction of the SARS-CoV-2 with human cells. This relationship results in a substantial increase in angiotensin II (Zou et al. 2020), peptide involved in the mechanisms of inflammation, apoptosis, profibrotic signaling, decreased alveolar fluid clearance, and remodeling in lung tissue (Ismael-Badarneh et al. 2015; Forrester et al. 2018).

In view of this emergency situation of global public health, and in an attempt to elucidate the pathophysiological mechanisms involved in ARDS, as observed in COVID-19, many studies have sought methodologies that allow the simulation of disease characteristics in protocols with animals. Among the methodologies, exposure to lipopolysaccharide (LPS) has been widely used, which produces an acute inflammatory pulmonary response similar to that seen in ARDS (Faffe et al. 2000), in addition to causing pulmonary fibrosis (Boskabadi et al. 2019) and increasing levels of angiotensin II (Hermanns et al. 2014). Acute lung injury, and consequent ARDS, induced by LPS has been the methodology used in studies that aim to evaluate the effectiveness of compounds against inflammatory processes related to COVID-19 (Wang et al. 
2020; May et al. 2020; McCord et al. 2020). In addition, there is a search for pharmacological alternatives that can alleviate or prevent the ARDS problem. Among the elements that make up biodiversity, plant species are the raw material for the manufacture of numerous inputs, especially phytotherapics that have pharmacological attributes used in the treatment of coronavirus disease 2019 (Chinsembu 2020; Komolafe et al. 2021).

Regarding preventive actions and plant species that have a high therapeutic potential, cashew trees stand out, Anacardium occidentale L., Anacardiaceae, a species widely distributed in Brazil, especially in the Caatinga biome. Its product with the greatest commercial value is the chestnut (almond), with a highly appreciated flavor and antioxidant properties (Halvorsen et al. 2002), where the liquid from the cashew nutshell (LCC) is extracted. The main purpose of the LCC is to protect the almond from predators, preserving its germinative capacity. It is one of the richest sources of phenolic compounds, consisting mainly of cardols, cardanols, and anacardic acids (De Lima et al. 2008).

Anacardic acids are fat-soluble compounds, where the alkyl groups vary in length and degree of unsaturation of the side chain, being characterized as monosaturated, diunsaturated, or triunsaturated. Its biological activities are due to the solubility of the phenolic moieties in the cell lipid regions and the antioxidant capacity of the double bonds in the lateral alkyl chain (Trevisan et al. 2006). Thus, the present study seeks to investigate the effects of anacardic acid moeno (AAM, 1) on ARDS caused by LPS, since AAM has already shown the ability to suppress cytokines and oxidizing molecules (Ha and Kubo 2005; Kubo et al. 2006; Trevisan et al. 2006; De Lima et al. 2008; Carvalho et al. 2013) besides angiotensin (Trevisan et al. 2018), and pathophysiological factors observed in viral diseases, specifically COVID- 19 . Accordingly, we perform the isolation of the compound in question, analysis of the mechanics of the respiratory system, histopathology, and lung parenchyma morphometry.

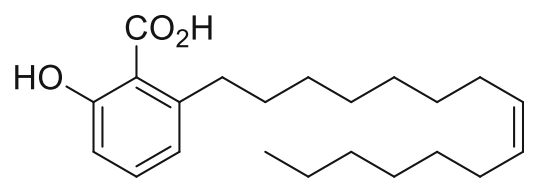

1

\section{Material and Methods}

\section{Material}

Cashew nutshell liquid (CNSL) was obtained from the Experimental Farm of the Brazilian Agricultural Research
Corporation (Embrapa). All of the materials provided were submitted to chromatography and characterized based on infrared spectroscopy (IR) and nuclear magnetic resonance (NMR).

\section{Extraction and Isolation}

The CNLS (23.5 g) was submitted to silica gel column chromatography and eluting with hexane, $\mathrm{CH}_{2} \mathrm{Cl}_{2}, \mathrm{CH}_{2} \mathrm{Cl}_{2} / \mathrm{EtOAc}$ (1:1), and EtOAc to afford four fractions. The EtOAc eluate was chromatographed on a silica gel column (CC) using the solvents $\mathrm{CH}_{2} \mathrm{Cl}_{2}$ and EtOAc afforded two fractions. The $\mathrm{CH}_{2} \mathrm{Cl}_{2}$ fraction was chromatographed on silica gel column successively eluted with hexane, $\mathrm{CH}_{2} \mathrm{Cl}_{2}, \mathrm{CH}_{2} \mathrm{Cl}_{2} / \mathrm{EtOAc}$ (1:1), and EtOAc to afford three subfractions. The $\mathrm{CH}_{2} \mathrm{Cl}_{2}$ / EtOAc (1:1) fraction provided the anacardic acid mixture (8.7 $\mathrm{g}$ ), which was further submitted to semi-preparative reversed phase $\mathrm{C}-18 \mathrm{HPLC}$, using $\mathrm{CH}_{3} \mathrm{CN} /\left(\mathrm{H}_{2} \mathrm{O} / \mathrm{CF}_{3} \mathrm{CO}_{2} \mathrm{H} 0.1 \%\right)$ as a mobile phase in an isocratic mode at a flow rate of $4 \mathrm{ml} / \mathrm{min}$ leading to the isolation of anacardic acid monoene (1).

\section{Animals}

Twenty male C57/black mice (7-8 weeks of age), with body weight of $25 \pm 5 \mathrm{~g}$, provided with water and feed ad libitum, were used in this study. Mice were housed in plastic cages under controlled environmental conditions.

\section{Pretreatment with AAM and Induction of Acute Lung Injury}

Twenty-four hours prior to the exposure to LPS, animals were pretreated orally with $100 \mathrm{mg} / \mathrm{kg}$ of AAM from CNSL diluted in $280 \mu \mathrm{l}$ of saline- $0.1 \%$ Tween 80 , or $280 \mu \mathrm{l}$ of vehicle (saline-0.1\% Tween 80). This concentration of AAM (100 $\mathrm{mg} / \mathrm{kg}$ ) was titrated based on a previous dose-dependent study (Carvalho et al. 2013).

Prior to exposure to LPS, the animals were sedated with sevofluorane (1 alveolar minimum concentration (AMC)). The instillation causes a reflex of apnea followed by deep inspiration that leads the fluid into the lung. Escherichia coli LPS (O55:B5 L2880, Sigma-Aldrich, St. Louis, MO) at a concentration of $1 \mu \mathrm{l} / \mathrm{g}$, or as a control sterile saline $(0.9 \%)$, was instilled at $1 \mu \mathrm{l} / \mathrm{g}$ of mouse body weight (Ribeiro et al. 2015). Twenty mice were randomly divided into three groups. In the first group (CTRL), the mice received $280 \mu$ l of vehicle (saline- $0.1 \%$ Tween 80 ) by gavage, and $24 \mathrm{~h}$ after pretreatment the mice were submitted to the ARDS negative control protocol previously mentioned. In the second group (LPS), the mice received $280 \mu \mathrm{l}$ of vehicle (saline- $0.1 \%$ Tween 80 ) by gavage, and $24 \mathrm{~h}$ after pretreatment the mice were submitted to the ARDS protocol. In the third group (AAM+LPS), the mice received $280 \mu \mathrm{l}$ of AAM $(100 \mathrm{mg} / \mathrm{kg})$ by gavage, and 
$24 \mathrm{~h}$ after pretreatment the mice were submitted to the ARDS protocol (Fig. S1).

\section{Respiratory System Mechanics}

All procedures for respiratory system mechanics analysis were previously reported (Gondim et al. 2019). In brief, the animals were anesthetized (ketamine:xylazine 100:10 mg/kg), tracheostomized, intubated (14-gauge cannula), and then connected to a computer-controlled ventilator for small animals (Scireq-flexiVent, Montreal, QC, Canada). The animals were ventilated at baseline settings, and paralyzed (pancuronium bromide $0.5 \mathrm{ml} / \mathrm{kg}$, i.p., Cristália, Brazil). Immediately after standardizing the mechanical history, the impedance of the respiratory system $\left(Z_{r s}\right)$ was measured by forced oscillation technique (Hantos et al. 1992), using 12 sequential $30 \mathrm{~s}$ sampling intervals, for a total of $6 \mathrm{~min}$ (12 total). Through the forced oscillation technique, data from Newtonian resistance $\left(\mathrm{R}_{\mathrm{N}}\right)$ was obtained, as well as tissue elastance $(\mathrm{H})$ and resistance $(\mathrm{G})$. Thereafter, two quasi-static PV curves were obtained an estimate of inspiratory capacity (IC), and PV loop area.

\section{Methacholine Challenge}

Immediately after measurements of respiratory system mechanics, two DI were done, followed by $5 \mathrm{~min}$ of ventilation with baseline settings. Airway smooth muscle hyperresponsiveness was evaluated by inhalation of methacholine (MCh) (Sigma-Aldrich, St. Louis, MI, USA) delivered by aerosol produced by an ultrasonic nebulizer (Inalasonic, NS, São Paulo, Brazil) coupled to the inspiratory line of the ventilator. For such purpose, $4 \mathrm{ml}$ of MCh solution $(30 \mathrm{mg} / \mathrm{ml}$ ) was added to the nebulizer container. The nebulization was carried out during $30 \mathrm{~s}$ under mechanical ventilationand the average amount delivered to the animal was $1.2 \mathrm{mg} / \mathrm{kg}$ of MCh solution. After nebulization, the same previous analysis was repeated (forced oscillation, $30 \mathrm{~s}$ sequential intervals for $6 \mathrm{~min}$ ), followed by two DI and another forced oscillation data gathering.

\section{Histological Study}

All procedures for histological analysis were previously reported (Gondim et al. 2019). In brief, immediately after the determination of respiratory system mechanics, the lungs were perfused with saline and then removed en bloc, and was kept at functional residual capacity and fixed in Millonig's formaldehyde (100 ml HCHO, $900 \mathrm{ml} \mathrm{H} 2 \mathrm{O}, 18.6 \mathrm{~g} \mathrm{NaH}_{2} \mathrm{PO}_{4}$, $4.2 \mathrm{~g}$ $\mathrm{NaOH}$ ). Slides containing lung sections were stained with hematoxylin and eosin (HE) and examined by optical microscopy. Quantitative analysis was performed using the fraction area of collapsed alveoli and the amount of polymorphonuclear (PMN) cells, determined by the point-counting technique.
The air-space enlargement was quantified by the mean linear intercept length of the distal air spaces $\left(\mathrm{L}_{\mathrm{m}}\right)$ (Knudsen et al. 2010). The bronchoconstriction index (BCI) was determined by counting the number of points in the airway lumen (NP) and intercepts through the airway wall (NI), using a reticulum and applying the equation $\mathrm{BCI}=\mathrm{NI} / \sqrt{\mathrm{NP}}$ (Sakae et al. 1994).

\section{Statistical Analysis}

Statistical analyses were performed using GraphPad Prism version 5.00 (GraphPad, San Diego, CA, USA). Results are presented as mean $\pm \mathrm{SD}$, where $n$ represents the number of samples. For comparison between groups, one-way analysis of variance (ANOVA) followed by the Student-NewmanKeuls test was used. Multiple comparisons were then corrected with a Bonferroni test. A difference was considered significant if $p<0.05$.

\section{Results and Discussion}

The natural product anacardic acid monoene (1) was isolated from the CNLS. The structure was elucidated by analysis of their 1D and 2D nuclear magnetic resonance (NMR) and by comparing their spectroscopy data with that reported in the literature (Morais et al. 2017). Its ${ }^{1} \mathrm{H}$ NMR spectrum displayed signals relative to the hydrogens of the double bond at $\delta 5.37$ with the integration of the hydrogens, in addition to signals relative to aromatic hydrogens at $\delta 6.78(\mathrm{~d}, 1 \mathrm{H}, \mathrm{H}-4)$, 7.37 (t, 1H, H-4), and $\delta 6.88(\mathrm{~d}, 1 \mathrm{H}, \mathrm{H}-6)$. The ${ }^{13} \mathrm{C} \mathrm{NMR}$ spectra of anacardic acid monoene showed 22 spectral lines of which, in comparison to ${ }^{13} \mathrm{C}$ NMR DEPT $135^{\circ}$, confirmed the presence of four non-hydrogenated, five methine, twelve methylene, and one methyl carbons (Fig. S2). To determine the purity of the chromatographic peak, a chromatograph (Shimadzu LC-20A, Kyoto, Japan) was used, equipped with an LC-20AT pump, SPD-M20A PDA detector (Diode Arrangement Detector) and CBM-20A controller system. Symmetry was observed, the peak purity curve was above zero, and the calculated purity index was equal to 0.9999998 (Fig. S3), indicating that there is no co-elution at peak 3 (Fig. S4), anacardic acid monoene (1).

Figure 1 shows the lung function data for the groups CTRL $\left(R_{N}=0.111 \pm 0.027, \mathrm{G}=2.68 \pm 0.47, \mathrm{H}=14.87 \pm 2.71, \mathrm{CI}=\right.$ $1.14 \pm 0.24$, PV loop area $=2.36 \pm 0.35)$, LPS $\left(\mathrm{R}_{\mathrm{N}}=0.209 \pm\right.$ $0.064, \mathrm{G}=4.95 \pm 1.15, \mathrm{H}=27.60 \pm 6.33, \mathrm{CI}=0.083 \pm 0.163$, PV loop area $=3.67 \pm 0.87)$, and AAM + LPS $\left(\mathrm{R}_{\mathrm{N}}=0.177 \pm\right.$ $0.052, \mathrm{G}=3.78 \pm 0.61, \mathrm{H}=20.25 \pm 3.94, \mathrm{CI}=0.94 \pm 0.20, \mathrm{PV}$ loop area $=2.68 \pm 0.50$ ) groups. Figure 1 also shows the variation in $\Delta \mathrm{R}_{\mathrm{N}}$ over time after administration of MCh (30 $\mathrm{mg} / \mathrm{ml}$ ) in all groups. We observed an increased $\Delta R_{N}$ at LPS 
Table 1 Morphometric parameters

\begin{tabular}{lllll}
\hline Groups & PMN cells $\left(\times 10^{-3} / \mu \mathrm{m}^{2}\right)$ & Collapsed alveolus $(\%)$ & BCI & Mean alveolar diameter $(\mu \mathrm{m})$ \\
\hline CTRL & $16.66 \pm 5.02$ & $7.88 \pm 3.85$ & $2.12 \pm 0.21$ & $47.04 \pm 4.87$ \\
LPS & $30.53 \pm 6.39^{\mathrm{a}}$ & $32.95 \pm 4.29^{\mathrm{a}}$ & $2.70 \pm 0.38^{\mathrm{a}}$ & $36.85 \pm 6.63^{\mathrm{a}}$ \\
AAM+LPS & $25.86 \pm 4.56^{\mathrm{a}}$ & $22.52 \pm 4.14^{\mathrm{a}}$ & $2.51 \pm 0.26^{\mathrm{b}}$ & $40.32 \pm 5.01^{\mathrm{b}}$ \\
\hline
\end{tabular}

Values are mean \pm SD of CTRL, LPS, and AAM+LPS groups. The data were collected in ten matched fields per mice. ${ }^{\text {a }}$ Difference from CTRL group $(p$

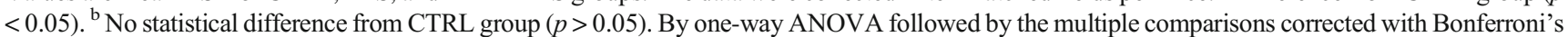
test. $P M N$, polymorphonuclear; $B C I$, bronchoconstriction index

in comparison to the CTRL group, demonstrating airway hyperresponsiveness (AHR). In addition, no statistical difference was observed when comparing the CTRL and AAM+
LPS groups. Figure 2 shows the PV curve graphs, for groups CTRL, LPS, and AAM+LPS. PV loops were generated using the data provided by the stepwise PVr-P maneuver. Figure 3

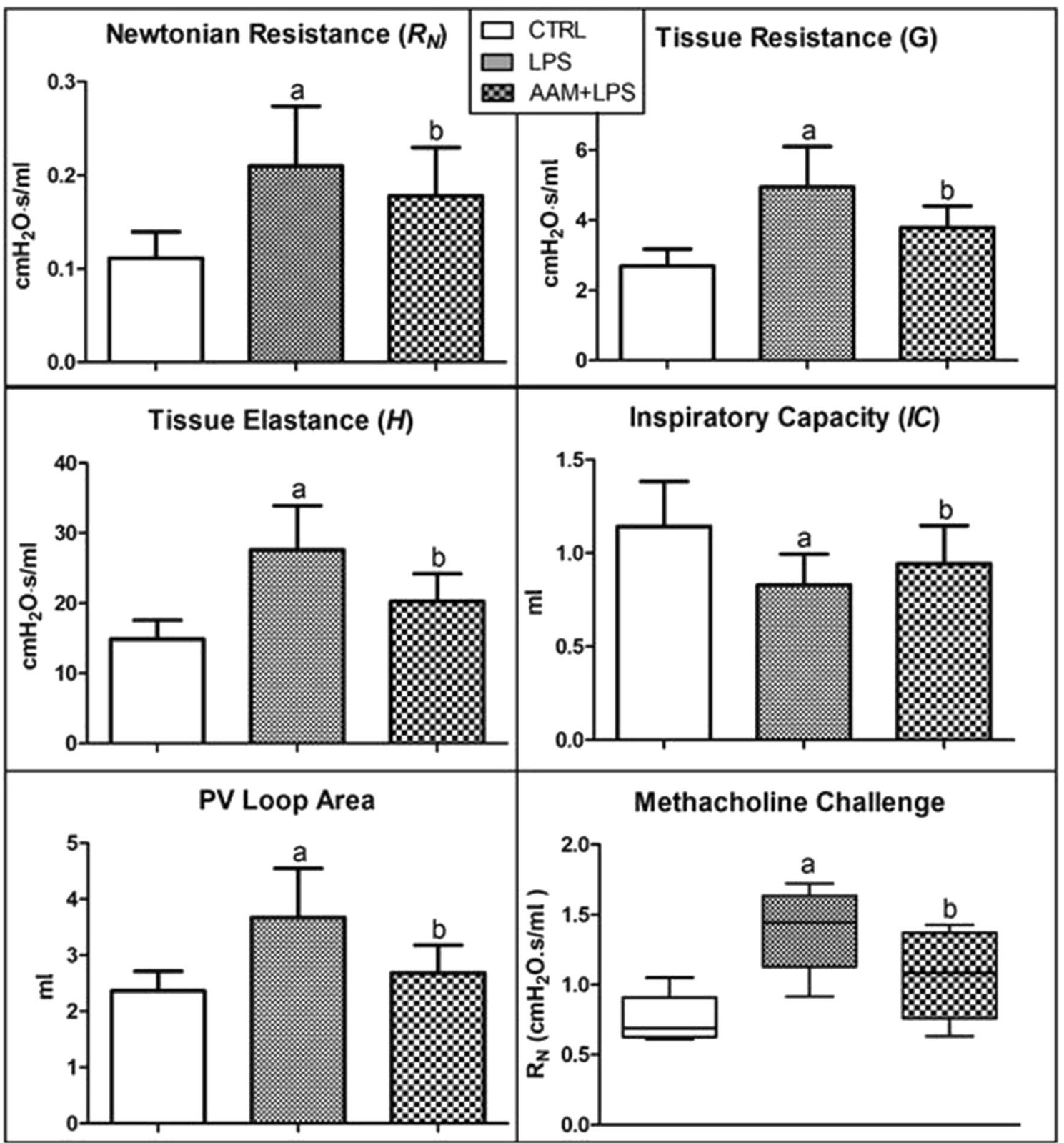

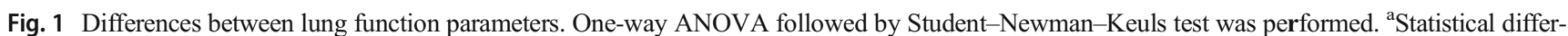
ence from CTRL group $(p<0.05)$. ${ }^{\mathrm{b}}$ No statistical difference from CTRL group $(p>0.05)$ 


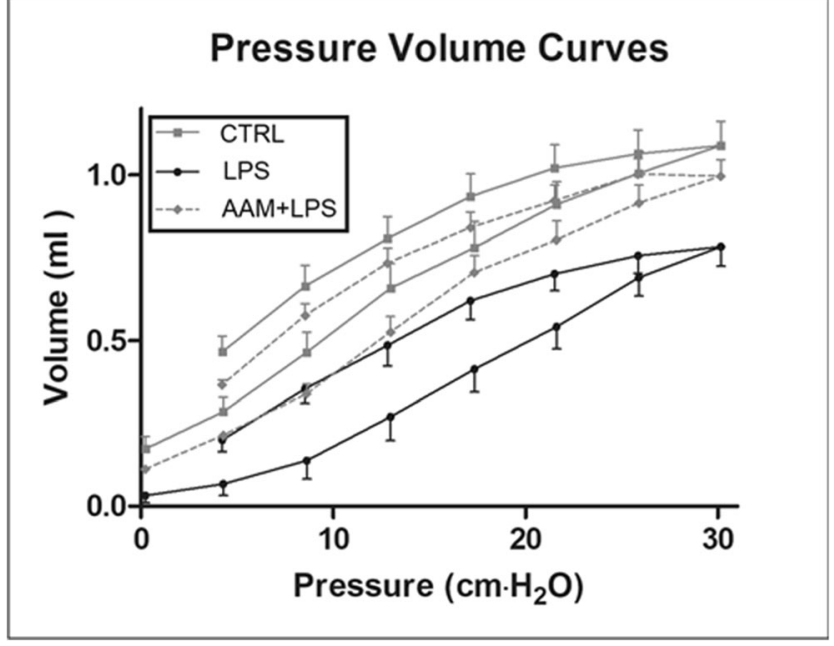

Fig. 2 PV curves for groups CTRL, LPS, and AAM+LPS

depicts representative lung and airway (inserts) histological images of the CTRL, LPS, and AAM+LPS groups. There was the presence of alveolar collapse, thickened septa, and cellular infiltration in the photomicrographs of the pulmonary parenchyma. Table 1 displays the alveolar collapse, amount of PMN cells, mean alveolar diameter, and BCI. We observed an increase in mean alveolar diameter and BCI of the LPS group when compared to that of the CTRL and AAM+LPS groups.

In ARDS, redox imbalance and pro-inflammatory cytokine production in the lungs is pathologically characterized by diffuse alveolar damage with numerous neutrophils and proteinrich edema in the alveolar space (Muir et al. 2016). For this reason, pulmonary infection, and especially damage to the alveoli, is a primary cause of morbidity viruses that affect the respiratory system, as in COVID-19 (Zhou et al. 2020). This pattern was observed in the present study (Table 1), where there was an increase in the number of PMN cells, an increase in the percentage of collapsed alveoli, and a decrease in the average alveolar diameter of animals in the LPS group when compared to the group CTRL. In addition, a tendency to decrease or neutralize these events was also observed when analyzing the AAM + LPS group, indicating that pretreatment with AAM prevented oxidative damage, and release of inflammatory cytokines and compounds capable of promoting edema, injury, and tissue deformation.

The antioxidant activity of anacardic acids can be attributed to the ability to suppress a variety of pro-oxidative enzymes involved in the production of reactive oxygen species (Ha and Kubo 2005; Sun et al. 2006), preventing the generation of superoxide anion (Musuoka and Kubo 2004; Trevisan et al. 2006) and potentiation of the antioxidant glutathione system present in the bronchial epithelium, type 2 alveolar cells, alveolar macrophages, and in the extracellular matrix (Carvalho et al. 2013), which together with the mucoid fluid that covers the airway epithelium, forms the first line of defense against toxic inhalants (Kinnula 2005; Kirkham and Rahman 2006). Redox imbalance and inflammatory processes can cause structural changes essential for tissue function, as it was observed in the mechanics of the respiratory system caused by ARDS induced by LPS.

In relation to our results, we assessed respiratory mechanics by the forced oscillation technique using a constant phase model and quasistatic PV curve (Fig. 1). In the constant phase model, the Newtonian resistance $\left(\mathrm{R}_{\mathrm{N}}\right)$ represents a good estimate of the total central airway resistance (Salazar and Knowles 1964), and tissue resistance (G) and tissue elastance $(\mathrm{H})$ are related to the intrinsic properties of the tissue (Fredberg and Stamenovic 1989). In the quasi-static PV curve, estimate of inspiratory capacity (IC) quantifies the volume of air received by the lungs up to a pressure of $30 \mathrm{cmH}_{2} \mathrm{O}$. PV loop area provides an estimate of the amount of atelectasis (airspace closure) that existed before the PV loop maneuver (Fredberg and Stamenovic 1989). The constant phase model parameters (Fig. 4) revealed a statistically significant increase in the values for airway resistance $\left(R_{N}\right)$, tissue resistance $(G)$, and tissue elastance $(\mathrm{H})$, when comparing the LPS group and CTRL group. Parameters $\mathrm{G}$ and $\mathrm{H}$ are related to pulmonary parenchyma rheology. However, the increased $R_{N}$ value, as a response to narrowing of the airways, promotes closure of the small airways and subsequent distortion of the pulmonary parenchyma (Wagers et al. 2002). It also influences tissue parameters $(\mathrm{G}$ and $\mathrm{H})$, contributing to an effectively smaller lung (Table 1, collapsed alveolus) with a proportionally larger

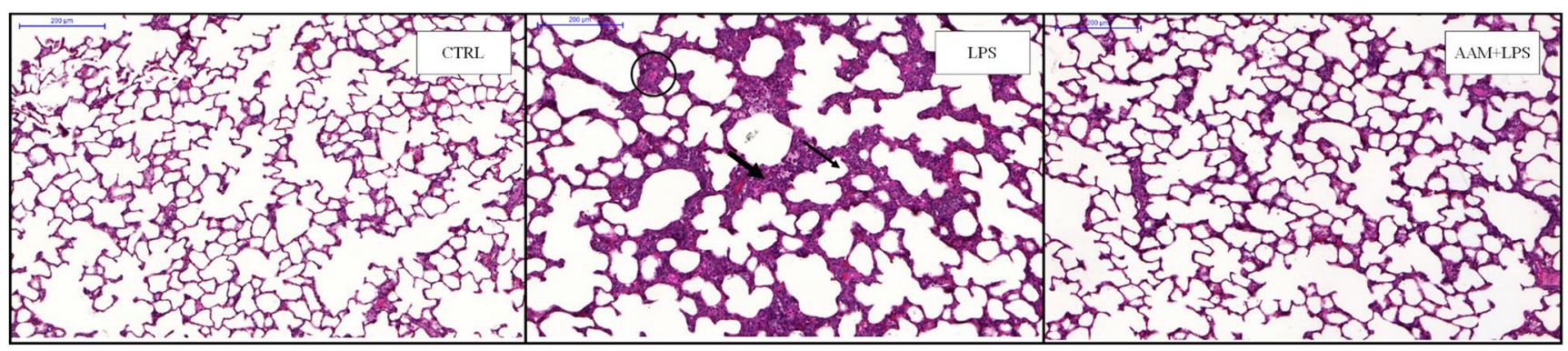

Fig. 3 Photomicrographs of lung parenchyma stained with hematoxylin-eosin of CTRL, LPS, and AAM+LPS groups. Thin arrows: thickened septa; thick arrows: cellular infiltrate; and circles: alveolar collapse 
$\mathrm{H}$. This would explain the increase in $\mathrm{H}$ values. Tissue resistance $(\mathrm{G})$ reflects the viscous energy dissipation in the lung tissue, a parameter that is also liable to change due to the lung parenchyma distortion that occurs when the airways contract (Wagers et al. 2002). This effect would be responsible for the increased $\mathrm{G}$ values. Additionally, the mean alveolar diameter decreases and the collapsed alveoli number increase (Table 1) all cause changes in the lung parenchyma, likely resulting in tissue remodeling and an increase in the $\mathrm{G}$ and $\mathrm{H}$ parameters. Regarding the airway resistance variation $\left(\Delta R_{N}\right)$, the parameter obtained after the MCh challenge, a statistically significant difference was observed for several points in the values for the LPS group when compared to the CTRL group (Fig. 4). Increased values of $\Delta R_{N}$ represent hyperresponsiveness of the airway muscle, which can be explained due to the narrowing (Table 1, BCI) or greater stiffness of airway smooth muscle, probably caused by the inflammatory process (Table 1, PMN Cells) (Serra et al. 2017).

Similar to COVID-19, angiotensin 2 is also seen in high concentrations in acute lung injury induced by LPS (Hermanns et al. 2014). This molecule has the ability to increase endothelial permeability in the surrounding capillaries (Bodor et al. 2012) and it also has pro-fibrotic effects on the fibroblasts that reside in the interstitial spaces around the alveoli, thereby increasing pulmonary fibrosis (Uhal et al. 2012; Boskabadi et al. 2019). These findings can be related to the results presented in the present study, where the analysis of the parameters obtained for the pressure-volume curves (Fig. 4) showed a statistically significant decrease in estimated inspiratory capacity (IC), as well as an increase in the PV curve area, when comparing the LPS group to the CTRL group. Decrease in IC corroborates the pulmonary tissue stiffening indicated by the increased $\mathrm{H}$ (Wagers et al. 2002). The PV curve area represents changes in the distribution of surfactant on the alveolar surface, and its increase may represent augmentation in the areas of atelectasis, which can be confirmed in the photomicrographic images (Fig. 3), considering the increment in the percentage of collapsed alveoli (Table 1).

\section{Conclusions}

The statistically significant differences found for all respiratory mechanics variables (Zrs and PV curve area) and challenge to $\mathrm{MCh}$, as well as for lung parenchyma morphometry (percentage of collapsed alveoli, PMN cells, mean alveolar diameter, and IBC), demonstrated significant changes in the animals in the LPS group when compared to those in the CTRL group, confirming the establishment of LPS-induced ARDS. In addition, the lack of changes observed for these variables among the animals in the AAM + LPS group when compared to the CTRL group may indicate the effectiveness of oral intake of $100 \mathrm{mg} / \mathrm{kg}$ of anacardic acid monoene in preventing acute respiratory distress syndrome caused by viral pathogens, demonstrating in vivo for the first time the effectiveness of an isolated anacardic acid.

Supplementary Information The online version contains supplementary material available at https://doi.org/10.1007/s43450-021-00151-8.

Author's Contribution FLG: conducting the research process, carrying out the experiments, and preparing the scientific writing. RNF: conducting experiments and histological analysis. DSS: application of statistical, mathematical, computational, and other formal techniques to analyze or synthesize study data. TRN: execution of the compound isolation technique and availability of reagents. MASR: provision of study materials, reagents, materials, and laboratory samples. ATAP: review and edition of the manuscript, and coordination of research activities. FSAC: supervision of methodologies, conceptualization ideas; inclusion or evolution of research objectives. All the authors approved the final version of the article.

Funding This study was financed in part by the Coordenação de Aperfeiçoamento de Pessoal de Nível Superior, Brazil (CAPES: Finance Code 001).

\section{Declarations}

Conflict of Interest The authors declare no competing interests. Protection of Animal Subjects

Protection of Animals and experimental procedures were approved by the Ethics Committee on the Use of Animals of the State University of Ceará (Protocol No. 5797919-2017). The experiments complied with the following guidelines: ARRIVE; the National Institutes of Health Guide for the Care and Use of Laboratory Animals (NIH Publications No. 8023, revised 1978), and the National Council for Controlling Animal Experimentation of the Ministry of Science, Technology and Innovation (CONCEA/MCTI), Brazil.

\section{References}

Bodor C, Nagy JP, Végh B, Németh A, Jenei A, MirzaHosseini S, Sebe, A, Rosivall L (2012) Angiotensin II increases the permeability and PV-1 expression of endothelial cells. A J PhysioCell Ph 302. https:// doi.org/10.1152/ajpcell.00138.2011

Boskabadi J, Askari VR, Hosseini M, Boskabady MH (2019) Immunomodulatory properties of captopril, an ACE inhibitor, on LPS-induced lung inflammation and fibrosis as well as oxidative stress. Inflammopharmacology 27:639-647. https://doi.org/10. 1007/s10787-018-0535-4

Carvalho ALN, Annoni R, Torres LHL, Durão ACCS, Shimada ALB, Almeida F, Hebeda CB, Lopes FDTQS, Dolhnikoff M, Martins MA, Silva LFF, Farsky SHP, Saldiva PHN, Ulrich CM, Owen RW, Marcourakis T, Trevisan MTS, Mauad T (2013) Anacardic acids from cashew nuts ameliorate lung damage induced by exposure to diesel exhaust particles in mice. Evid Based Compl Alt Article ID 549879. https://doi.org/10.1155/2013/549879

Chinsembu KC (2020) Coronaviruses and nature's pharmacy for the relief of coronavirus disease 2019. Rev Bras Farmacogn 30:603621. https://doi.org/10.1007/s43450-020-00104-7

De Lima SG, Feitosa CM, Citó AMGL, Moita Neto JM, Lopes JAD, Leite AS, Brito MC, Dantas SMM, Cavalcante AACM (2008) Effects of immature cashew nut-shell liquid (Anacardium occidentale) against oxidative damage in Saccharomyces cerevisiae 
and inhibition of acetylcholinesterase activity. Genet Mol Res 7: 806-818. https://doi.org/10.4238/vol7-3gmr473

Faffe DS, Seidl VR, Chagas PS, De Moraes VG, Capelozzi VL, Rocco PR, Zin WA (2000) Respiratory effects of lipopolysaccharideinduced inflammatory lung injury in mice. Eur Respir J 15:85-91. https://doi.org/10.1183/09031936.00.15108500

Fredberg JJ, Stamenovic D (1989) On the imperfect elasticity of lung tissue. J Appl Physiol 67:2408-2419. https://doi.org/10.1152/jappl. 1989.67.6.2408

Forrester SJ, Booz GW, Sigmund CD, Coffman TM, Kawai T, Rizzo V, Scalia R, Eguchi S (2018) Angiotensin II signal transduction: an update on mechanisms of physiology and pathophysiology. Physiol Rev 98:1627-1738. https://doi.org/10.1152/physrev.00038.2017

Gondim FL, Serra DS, Cavalcante FSÁ (2019) Effects of eucalyptol in respiratory system mechanics on acute lung injury after exposure to short-term cigarette smoke. Respir Physiol Neurobi 266:33-38. https://doi.org/10.1016/j.resp.2019.04.007

Ha TJ, Kubo I (2005) Lipoxygenase inhibitory activity of anacardic acids. J Agric Food Chem 53:4350-4354. https://doi.org/10.1021/jf048184e

Halvorsen BL, Holte K, Myhrstad MC, Barikmo I, Hvattum E, Remberg SF, Wold AB, Haffner K, Baugerød H, Andersen LF, Moskaug JØ, Jacobs DR, Blomhoff R (2002) A systematic screening of total antioxidants in dietary plants. J Nutr 132:461-471. https://doi.org/ $10.1093 / \mathrm{jn} / 132.3 .461$

Hantos Z, Daroczy B, Suki B, Nagy S, Fredberg JJ (1992) Input impedance and peripheral inhomogeneity of dog lungs. J Appl Physiol 72: 168-178. https://doi.org/10.1152/jappl.1992.72.1.168

Hermanns M, Muller A, Tsokos M, Kirkpatrick C (2014) LPS-induced effects on angiotensin I-converting enzyme expression and shedding in human pulmonary microvascular endothelial cells. In Vitro Cell Dev Biol Anim 50:287-295. https://doi.org/10.1007/s11626013-9707-0

Ismael-Badarneh R, Guetta J, Klorin G, Berger G, Abu-saleh N, Abassi Z, Azzam ZS (2015) The role of angiotensin II and cyclic AMP in alveolar active sodium transport. PloS One 10:e137118. https://doi. org/10.1371/journal.pone.0137118

Kinnula VL (2005) Focus on antioxidant enzymes and antioxidant strategies in smoking related airway diseases. Thorax 60:693-700. https://doi.org/10.1136/thx.2004.037473

Kirkham P, Rahman I (2006) Oxidative stress in asthma and COPD: antioxidants as a therapeutic strategy. Pharmacol herapeut 111: 476-494. https://doi.org/10.1016/j.pharmthera.2005.10.015

Knudsen L, Weibel ER, Gundersen HJG, Weinstein FV, Ochs M (2010) Assessment of air space size characteristics by intercept (chord) measurement: an accurate and efficient stereological approach. J ppl Physiol 108:412-421. https://doi.org/10.1152/japplphysiol. 01100.2009

Komolafe K, Komolafe TR, Fatoki TH, Akinmoladun AC, Brai BIC, Olaleye MT, Akinda AA (2021) Coronavirus disease 2019 and herbal therapy: pertinent issues relating to toxicity and standardization of phytopharmaceuticals. Rev Bras Farmacogn. 10.1007/ s43450-021-00132-x

Kubo I, Masuoka N, Ha TJ, Tsujimoto K (2006) Antioxidant activity of anacardic acids. Food Chem 99:555-562. https://doi.org/10.1016/j. foodchem.2005.08.023

May M, Slitzky M, Rostama B, Barlow D, Houseknecht KL (2020) Antipsychotic-induced immune dysfunction: a consideration for COVID-19 risk. Brain Behav Immun Health 6:100097. https://doi. org/10.1016/j.bbih.2020.100097

McCord JM, Hybertson BM, Cota-Gomez A, Geraci KP, Gao B (2020) $\mathrm{Nrf} 2$ activator $\mathrm{PB} 125 \AA$ as a potential therapeutic agent against COVID-19. Antioxidants 9:518. https://doi.org/10.3390/antiox9060518

Morais SM, Silva KA, Araujo H, IGP V, Alves DR, Fontenelle ROS, Silva AMS (2017) Anacardic acid constituents from cashew nutshell liquid: NMR characterization and the effect of unsaturation on its biological activities. Pharmaceuticals 10:31. https://doi.org/10. 3390/ph10010031

Muir R, Osbourn M, Dubois AV, Doran E, Small DM, Monahan A, O'Kane CM, McAllister K, Fitzgerald DC, Kissenpfennig A, McAuley DF, Ingram RJ (2016) Innate lymphoid cells are the predominant source of IL-17A during the early pathogenesis of acute respiratory distress syndrome. Am J Respir Crit Care 193:407-416. https://doi.org/10.1164/rccm.201410-1782OC

Ribeiro A, Almeida VI, Costola-de-Souza C, Ferraz-de-Paula V, Pinheiro ML, Vitoretti LB, Gimenes-Junior JA, Akamine AT, Cripa JA, Tavares-de-Lima W, Palermo-Neto J (2015) Cannabidiol improves lung function and inflammation in mice submitted to LPS-induced acute lung injury. Immunopharm Immunot 37:35-41. https://doi. org/10.3109/08923973.2014.976794

Ruan Q, Yang K, Wang W, Jiang L, Song J (2020) Clinical predictors of mortality due to COVID-19 based on an analysis of data of 150 patients from Wuhan, China. Intens Care Med 46:846-848. https://doi.org/10.1007/s00134-020-05991-x

Sakae RS, Leme AS, Dolhnikoff M, Pereira PM, Do Patrocinio M, Warth TN, Zin WA, Saldiva PH, Martins MA (1994) Neonatal capsaicin treatment decreases airway and pulmonary tissue responsiveness to methacholine. Am J Physiol 266:L23-L29. https://doi.org/10.1152/ ajplung.1994.266.1.L23

Salazar E, Knowles JH (1964) An analysis of pressure-volume characteristics of the lungs. J Appl Physioloy 19:97-104. https://doi.org/10. 1152/jappl.1964.19.1.97

Serra DS, Brito KBPD, Oliveira KL, Oliveira MLM, Cavalcante FSÁ (2017) Respiratory system of rats exposed to pollutants arising out of heating residual glycerol. J Fundam Renewable Energy Appl 7. https://doi.org/10.4172/2090-4541.1000220

Sun Y, Jiang X, Chen S, Price BD (2006) Inhibition of histone acetyltransferase activity by anacardic acid sensitizes tumor cells to ionizing radiation. FEBS Lett 580:4353-4356. https://doi.org/10.1016/j. febslet.2006.06.092

Trevisan MTS, Pfundstein B, Haubner R, Würtele G, Spiegelhalder B, Bartsch H, Owen RW (2006) Characterization of alkyl phenols in cashew (Anacardium occidentale) products and assay of their antioxidant capacity. Food Chem Toxicol 44:188-197. https://doi.org/ 10.1016/j.fct.2005.06.012

Trevisan MTS, Ricarte I, Dos Santos SJM, Almeida WP, Ulrich CM, Owen RW (2018) Inhibition of angiotensin I converting enzyme by anacardic acids isolated from cashew nut (Anacardium occidentale Linn.) shell liquid. Int J Food Prop 21:921-929. https://doi.org/10.1080/10942912.2018.1460756

Uhal BD, Li X, Piasecki CC, Molina-Molina M (2012) Angiotensin signalling in pulmonary fibrosis. Intl J Biochem Cell B 44:465468. https://doi.org/10.1016/j.biocel.2011.11.019

Wagers S, Lundblad LK, Moriya HT, Bates JH, Irvin CG (2002) Nonlinearity of respiratory mechanics during bronchoconstriction in mice with airway inflammation. J Appl Physiol 92:1802-1807. https://doi.org/10.1152/japplphysiol.00883.2001

Wang Z, Wang Y, Vilekar P, Yang S, Gupta M, Oh MI, Meek A, Doyle L, Villar L, Brennecke A, Liyanage I, Reed M, Barden C, Weaver DF (2020) Small molecule therapeutics for COVID-19: repurposing of inhaled furosemide. PeerJ 8:e9533. https://doi. org/10.7717/peerj.9533

Zhou F, Yu T, Du R, Fan G, Liu Y, Liu Z, Xiang J, Wang Y, Song B, Gu X, Wei Y, Li H, Wu X, Xu J, Tu S, Zhang Y, Chen H, Cao B (2020) Clinical course and risk factors for mortality of adult inpatients with COVID-19 in Wuhan, China: a retrospective cohort study. Lancet 395:1054-1062. https://doi.org/10.1016/S0140-6736(20)30566-3

Zou X, Chen K, Zou J, Han P, Hao J, Han Z (2020) Single-cell RNA-seq data analysis on the receptor ACE2 expression reveals the potential risk of different human organs vulnerable to $2019-\mathrm{nCoV}$ infection. Front Med 14:185-192. https://doi.org/10.1007/s11684-020-0754-0 